\title{
Hilfe für eine wunde Seele
}

\section{Enrico Danieli}

Dieser Artikel ist als Ergänzung zum Editorial Doctors' health matters von Barbara Weil in der SÄZ 25/2015 gedacht.
Dr. med. Enrico Danieli Via ai Colli 22

CH-6648 Minusio

e.b.danieli[at]bluewin.ch
Es kommt schleichend, die Gedanken gehen vermehrt eigene Wege, kreisen, Sie werden ungeduldig mit sich, mit den Patienten, reizbar, überempfindlich, verwundbar. Vieles erscheint überflüssig, sinnlos, es ist, als ob Sie mehr Aufwand zu betreiben hätten als früher. Sie plagen sich seit Wochen, Monaten, jetzt fällt Einfaches schwer: Zuhören, Untersuchen, Organisieren - zu allem müssen Sie sich überwinden. Und doch tun Sie Ihre Arbeit wie gewohnt, mehr mechanisch, die Gefühle fehlen. Ja, Sie tun das alles, aber eigentlich noch mehr: Sie verheimlichen Ihre Schwierigkeiten, denn von diesen darf niemand erfahren, und Sie betreiben, um sich zu verstecken, einen grossen Kraftaufwand. Es ist da etwas, das Sie belastet: Sie vertragen nichts mehr, alles schmerzt. Verschiedene Mood-Stabilisatoren haben Sie ausprobiert, keiner hilft. Sie spüren, endlich, dass Sie Hilfe brauchen, Sie fühlen sich in der Seele verwundet, immer fremder. Doch davon darf niemand erfahren, in unserem Beruf ist das verheerend. Und es erzählt sich weiter, wird zur Schauergeschichte, das Vertrauen ist weg. Wo holen Sie Hilfe? Sie kennen viele Kollegen aus der täglichen Arbeit - doch das geht nicht, und auf Empfehlung jemanden zu kontaktieren, ist heikel. Sie suchen sich einen Therapeuten, ja, Sie benötigen dringend einen Psychotherapeuten, eine Psychiaterin, einen Psychiater. Sie stellen aus dem Internet eine Liste zusammen mit Namen, die Fotografien meiden Sie, gibt es doch Gesichter, die man nicht mag. Zu telefonieren fällt schwer, schon die Stimme gegenüber kann Mühe bereiten.

\section{Sie fühlen sich in der Seele verwundet, immer} fremder. Doch davon darf niemand erfahren.

Und dann vor allem: Was sagen Sie? Wie kann man sich in wenigen Sekunden erklären? Sie folgen dem Alphabet, suchen sich einen ruhigen Moment, Sie sind allein. Telefonieren. Schwitzen. Sie überlegen sich Ihre Worte. Es läutet und läutet. Nichts. Später noch einmal. Wieder nichts. Ein zweiter Versuch. Wieder die gleiche Überwindung, wieder das Warten auf einen ungestörten Moment, wieder die gleiche Anspannung. Diesmal ist die Leitung besetzt. Wieder besetzt. Ein ellenlanges Gespräch, beim Psychiater wohl möglich. Ohne Ende.
Nur besetzt. Der Mut beginnt Sie zu verlassen. Man will mich nicht, denken Sie. Vielleicht übertreibe ich ja, ist alles ganz ohne Bedeutung, eine momentane Baisse, mehr nicht. Einige Wochen warten Sie. Nein, es geht nicht, Sie finden keinen Ausweg. Ein neuer Versuch, neue Namen, andere Adressen. Der Telefonbeantworter. $\mathrm{Zu}$ hinterlegen sind Name, Vorname, Grund des Anrufs und Rückrufnummer. Man werde so bald als möglich sich melden. Bei «Grund des Anrufs» zögern Sie. Sie können es nicht sagen, Sie wollen keine Diagnose liefern, doch dann - wozu rufen Sie an? Einige Möglichkeiten verwerfen Sie, schliesslich entscheiden Sie sich für Verwundung. Ja, das ist es wohl am ehesten. Sie warten auf den Rückruf. Stundenlang. Dieser ist sowieso unangenehm, denn er wird Sie treffen in einem

\section{Vielleicht übertreibe ich ja, ist alles ganz} ohne Bedeutung, eine momentane Baisse, mehr nicht.

ungünstigen Moment. Doch niemand ruft an. Niemand ruft zurück. Auch bei der nächsten Adresse. Nichts. Einmal ein Anruf auf Ihrem Handy, zweimal, Sie rufen zurück, doch da ist wieder das Tonband - so geht es weiter, immer weiter. Es ist zum Verzweifeln.

Man will Sie nicht, man hat genug Patienten. Ja, das ist es wohl. Beim fünfzehnten Anruf gelingt ein direktes Gespräch. Wieder haben Sie Name, Vorname und Beruf anzugeben (das ist unangenehm), den Grund des Anrufs, diese Antwort ist nun schon Standard, auch wenn er, auf der anderen Seite, Schweigen hervorruft, und dann kommt noch die Frage, wie man zu dieser Adresse gekommen sei, durch Empfehlung, persönliche Kenntnisse oder Telefonbuch. So wie gefordert, beantworten Sie die Fragen, und Sie hoffen, hoffen innigst auf einen Termin, baldmöglichst. Um immer, immer wieder zu erfahren, dass man voll sei, übervoll, pumpenvoll, ein Termin erst in drei Monaten, in einem halben Jahr oder in einem Jahr möglich sei. Jetzt, spätestens, geben Sie auf - um dann auf der Geschlossenen der Psychiatrischen daran erinnert zu werden, was, neben dem eigenen Zögern, alles fatal gewesen ist. Doch das interessiert niemanden mehr, es ist schliesslich längst vergangen. 